\title{
Does the number of previous mood episodes moderate the relationship between alcohol use, smoking and mood in bipolar outpatients?
}

Wendela G. ter Meulen ${ }^{*}$ (D, Jan van Zaane, Stasja Draisma, Aartjan T.F. Beekman and Ralph W. Kupka

\begin{abstract}
Background: Evidence suggests that alcohol use and smoking are negatively associated with mood in bipolar disorders (BD). It is unknown if this relationship is moderated by the number of previous mood episodes. Therefore, this paper aims to examine whether the number of previous mood episodes moderates the relationship between alcohol use and smoking, and mood.

Method: This study assessed the outcomes of 108 outpatients with BD I and II in a prospective observational cohort study. For 1 year, subjects daily registered mood symptoms and substance use with the prospective Life Chart Method. The relationship between the average daily consumption of alcohol and tobacco units in the whole year and mood were examined by multiple linear regression analyses. Number of previous mood episodes, grouped into its quartiles, was added as effect moderator. Outcome was the number of depressive, hypomanic and manic days in that year.
\end{abstract}

Results: The number of depressive days in a year increased by $4 \%$ (adjusted $\beta$ per unit tobacco $=1.040$; $95 \% \mathrm{Cl} 1.003-1.079 ; p=0.033$ ) per unit increase in average daily tobacco consumption in that same year. Interaction analyses showed that in those subjects with less than 7 previous mood episodes, the number of manic and hypomanic days increased by $100.3 \%$ per unit increase in alcohol consumption (adjusted $\beta$ per unit alcohol $=2.003 ; 95 \% \mathrm{Cl} 1.225-3.274 ; p=0.006$ ). In those with 7 to 13 previous mood episodes, the number of manic and hypomanic days decreased by $28.7 \%$ per unit increase in alcohol consumption (adjusted $\beta$ per unit alcohol $=0.713 ; 95 \% \mathrm{Cl} 0.539-0.944 ; p=0.019$ ); and in subjects with 14 to 44 previous mood episodes, the number of manic and hypomanic days decreased by $7.2 \%$ per unit increase in tobacco consumption (adjusted $\beta$ per unit tobacco $=0.928 ; 95 \% \mathrm{Cl} 0.871-0.989 ; p=0.021$ ).

Conclusions: The number of previous mood episodes moderates the relationship between alcohol use and smoking and mood; and smoking is adversely associated with the number of depressive days.

Keywords: Kindling, Alcohol, Smoking, Bipolar disorders

\footnotetext{
*Correspondence: W.terMeulen@ggzingeest.nl

GGZ inGeest and Department of Psychiatry, Amsterdam Public Health

research institute, VU University Medical Center, A.J. Ernststraat 1187, 1081,

$\mathrm{HL}$, Amsterdam, The Netherlands
} 


\section{Background}

Bipolar disorder (BD) is a relatively common mood disorder, with a lifetime prevalence of $1.3 \%$ in the adult Dutch population [1] and estimates of $1-3 \%$ worldwide [1]. On average, patients spend more time in depressive than in manic or hypomanic episodes [2]. Even when patients receive adequate treatment, the naturalistic course of $\mathrm{BD}$ is characterized by recurrences of manic, hypomanic and depressive episodes [3], that occur in up to $50 \%$ of $\mathrm{BD}$ patients within one year after recovery from a mood episode and in up to $90 \%$ of BD patients during their lifetime [4]. Therefore, it is relevant to identify those factors that impact on mood, as these factors may be a target for intervention.

Alcohol use and smoking are frequent co-travelers with BD [5-7] and a growing body of evidence suggests that these substances may adversely affect mood in subjects with BD. For example, alcohol use disorder (AUD) was associated with a worse presentation of acute mania, more affective episodes, increased mood recurrence and increased rapid cycling in cross-sectional studies (for an overview: see [7]). Prospective studies have reported an increased risk of depressive relapse and mood recurrence in those with AUD compared to those without AUD [8-10]. Likewise, smoking was associated with more rapid cycling, an increased frequency of depressive and manic episodes, and a higher symptom severity in cross-sectional studies $[11,12]$. Prospective studies have demonstrated worse Clinical Global Impression BD (CGI-BD) scores and lengthier hospital stays [12]. Although explanations for the association between alcohol, smoking and mood are multidirectional $[7,13,14]$, the adverse relationship between alcohol use and smoking, and mood may be mediated by neuropathogenic changes including neurochemical alterations and oxidative stress $[13,15,16]$.

By contrast, a number of studies found no relationship between alcohol and smoking on the one hand, and mood on the other in BD [13, 17-19]. This inconclusiveness between studies may first be explained by methodological caveats, including few prospective studies, large heterogeneity in definitions of alcohol use and smoking, and divergent analytic approaches to investigate either shorter- or longer term effects. Furthermore, the relationship between alcohol use, smoking and mood may depend on the number of previous mood episodes: Post et al.'s kindling theory [20-22] states that the initial episodes of affective disorders are often precipitated by exogenous stressors whereas mood episodes tend to occur more autonomously after successive recurrences. In unipolar depression for example, the association between stressful life events and depression progressively declines with increasing episode number [20, 23]. Likewise, cognitive behavioral therapy (CBT) and pharmacological treatment are more effective in those BD subjects with few compared to multiple episodes [24-26]. Thus, alcohol and smoking may predominantly interact with mood in $\mathrm{BD}$ subjects with few compared to multiple previous mood episodes. One study [8] showed that AUD increases the risk of hospital re-admission for a new bipolar mood episode during the first episodes (measured as admissions), but not after multiple re-admissions.

To our knowledge, no research to date has investigated if such a "window of vulnerability" exists for the relationship between alcohol use, smoking and mood in BD subjects with fewer compared to multiple episodes. Therefore, this paper aims to examine whether the number of previous mood episodes moderates the association between the amount of alcohol use and smoking in one year, and the number of experienced depressive, hypomanic and manic days in that same year of follow up of daily life chart scores. We hypothesized that the amount of consumed alcohol and cigarettes is negatively associated with mood in BD, and that these associations are most pronounced in those subjects who have experienced fewer compared to multiple lifetime mood episodes.

\section{Methods}

Study sample and recruitment

We used the data of the Alcohol, Drugs and Stimulants (ADS) study of van Zaane et al. [18, 27] in a secondary analysis. This is a prospective study with the aim to investigate the effects of daily ADS intake on the course and outcome of patients with BD during a whole year through daily life chart recordings. The inclusion of subjects took place between June 2003 and November 2005. Exclusion criteria and assessment procedures are described in detail elsewhere [17]. Briefly, subjects were considered for enrolment in the ADS-study if they were aged 18-75 years and met criteria of BD I or II as assessed by the Structured Clinical Interview for DSM-IV (SCID-I; [28]). Outpatients were approached from mental hospitals, an addiction treatment center, and through the Dutch Association for Manic-Depressive Patients and Relatives. A total of 158 subjects met the inclusion criteria and completed baseline assessment. Out of these 158, a total of 108 subjects (68\%) aged 23-68 completed daily life charts during the whole year. Reasons for the 50 non-completers were: aversion or non-adherence to the daily registrations $(n=22)$, too severe mood symptoms $(n=4)$, death due to liver coma $(n=1)$, daily registrations too confrontational $(n=4)$, and unknown reasons $(n=23)$. Compared to completers, non-completers were more often male; no other significant baseline sociodemographic or clinical differences were found.

\section{Ethics}

The ADS study was approved by the Medical Ethical Review Committee of the University Medical Center 
Utrecht, The Netherlands. All subjects gave written informed consent after full explanation of the study.

\section{Assessments}

Data were collected at baseline by a team of mental health care professionals who were trained to perform the SCID-I by RWK. The SCID-I assessment included number of previous mood episodes, history of rapid cycling, and comorbid diagnoses such as anxiety, alcohol and other substance use disorders. A baseline Clinical Global Impressions Scale-Bipolar Version (CGI-BD [28]) score was obtained. Additional data were obtained with the Network Enrollment Questionnaire (NEQ) of the former Stanley Foundation Bipolar Network [29]. The NEQ assesses demographic, social and clinical characteristics, including family history of psychiatric illness, and various details about alcohol consumption and smoking. For a period up to one year subjects daily completed the National Institute of Mental Health prospective Life Chart Methodology (NIMH-LCM-p, further referred to as LCM-p [30]). At baseline and at every monthly visit during follow up, the LCM registrations were checked and approved by the research assistants, who were psychologists with ample clinical experience. Subjects got written and verbal instructions to daily assess their mood symptoms and severity, the related level of dysfunction, medication use, consumption of alcohol, cigarettes and other substances with the LCM-p.

\section{Definition of outcome}

The LCM-p allows measurement of the severity of mood symptoms and related level of dysfunction from both affective poles on a 5 -point scale $(0=$ no, $2.5=$ mild, $5=$ low moderate, $7.5=$ high moderate, and $10=$ severe dysfunction). As previous studies showed inconsistent results regarding the relationship between alcohol use and smoking on the one hand and either depressive or (hypo) manic outcomes on the other hand, we assessed both affective poles separately. The outcome measures, based on the complete year of the study, therefore were: 1. number of depression days (LCM-p mood score per 1 day of at least low moderate depression); and 2. number of hypomania and mania days (LCM-p mood score per 1 day of at least mild mania).

\section{Definition of alcohol and smoking}

Subjects daily scored their alcohol and tobacco consumption with the LCM-p. One unit of alcohol was defined as $12 \mathrm{~mL}$ pure alcohol equaling $100 \mathrm{~mL}$ of wine (12\% alcohol), $250 \mathrm{~mL}$ of beer ( $5 \%$ alcohol), or $35 \mathrm{~mL}$ of liquor (35\% alcohol), according to the Netherlands Institute for Mental Health (https://www.trimbos.nl). One tobacco product was defined as one cigarette, including self-rolled cigarettes from common tobacco, regardless of nicotine content. We calculated the average numbers of alcohol units and tobacco products per day based on the whole year of LCM-p registration.

\section{Confounders for the effects of alcohol and smoking} Confounders were chosen based on a priori hypotheses. Adjustments were made for age at intake in the ADS study, gender and socioeconomic status as measured by level of income [31-33]. Age at onset of BD was also considered a possible confounder [34-36]. Rapid cycling [37] was not entered as a confounder in the model due to collinearity with number of episodes.

\section{Effect modification: Number of mood episodes}

The number of mood episodes that subjects had experienced in their lifetime was based on the SCID-I assessment, or on the NEQ if this variable was not available from the SCID-I $(n=1)$. To investigate effect modification, this variable was grouped into its quartiles that successively consisted of less than 7,7 to 13,14 to 44 , and more than 44 mood episodes.

\section{Statistical analysis}

The baseline sociodemographic and clinical characteristics of all BD subjects were summarized using descriptive statistics. To give a clinical impression of sample characteristics, bivariate differences were calculated for low and high number of episodes, based on the median number of mood episodes at baseline as cutoff, which in our sample coincided with 13 episodes. For categorical data, $p$-values were calculated with the Chi-square test. For the numerical data, unpaired t-tests (if normally distributed data) and Mann-Whitney $U$ tests (if nonnormally distributed data) were used for comparing between groups. For all tests, a $p$-value of $<0.05$ was regarded as statistically significant.

Because the numbers of hypomanic, manic and depressive days were positively skewed, we applied natural logarithmic (ln) transformation on these outcome scores, which enabled multiple linear regression analyses. This analytic approach was chosen to focus attention on the moderating effect of number of previous episodes on the relationship between alcohol and smoking and the number of experienced ill days (either depressed or (hypo)manic) during a whole year. The hypothesis that the average daily consumption of alcohol and cigarettes is negatively associated with mood in $\mathrm{BD}$, was tested by multiple linear regression analyses with linear alcohol and smoking predictor variables, and without interaction terms. Adjusted beta's $(\beta)$ and their $95 \%$ confidence intervals (CIs) were calculated. The main hypothesis - that the associations between the amounts of alcohol use, smoking and mood are most pronounced in those subjects who have experienced fewer compared to multiple 
lifetime mood episodes - was tested by the addition of interaction terms to the regression models. These interaction terms were created by multiplying the quartiles of number of episodes by respectively the alcohol and smoking variables. The omnibus interaction term was considered significant at a $p$-value of $<0.05$.

Analyses were conducted using IBM SPSS Statistics version 22.0 (SPSS Inc., Chicago, USA). Confounders included in the models were selected by enter method and using a $p$-value of $<0.05$.

\section{Results}

\section{Baseline characteristics}

Sample characteristics, including sociodemographic and clinical characteristics, of the 108 patients are presented in Table 1. From this table it can be seen that the mean duration of illness was 22.3 years, and the median number of previous mood episodes 13.5 (IQR 7.0-46.3). Significant differences between those with multiple $(>13)$ compared to fewer $(\leq 13)$ episodes included a higher age at intake, more rapid cycling, and a greater duration of illness.

\section{Alcohol use and smoking}

Alcohol consumption was not associated with more depressive or hypomanic and manic days for the whole year, after adjustment for confounders (adjusted $\beta$ 's at a $p$-value of $>0.05$, see Table 2). The number of depressive days independently increased by $4.0 \%$ per unit increase in tobacco consumption per year (adjusted $\beta$ per unit tobacco $=1.040 ; 95 \%$ CI 1.003-1.079; $p=0.033$ ).

\section{Interaction analyses}

Interaction analyses showed that the number of previous mood episodes moderated the associations between alcohol use and smoking, and number of days ill. First, in those subjects in the first quartile, with less than 7 previous mood episodes, one unit increase in alcohol consumption increased the number of manic and hypomanic days by $100.3 \%$ (adjusted $\beta$ per unit alcohol $=2.003 ; 95 \%$ CI $1.225-3.274 ; p=0.006$ ). Second, in those subjects in the second quartile, with 7 to 13 previous mood episodes, one unit increase in alcohol consumption decreased the number of manic and hypomanic days by $28.7 \%$ (adjusted $\beta$ per unit alcohol $=0.713$; 95\% CI 0.539-0.944; $p=0.019$ ). Third, in those subjects in the third quartile, with 14 to 44 previous mood episodes, one unit increase in tobacco consumption decreased the number of manic and hypomanic days by $7.2 \%$ (adjusted $\beta$ per unit tobacco $=0.928 ; 95 \% \mathrm{CI}$ $0.871-0.989 ; p=0.021)$. In the remaining quartiles, number of episodes did not moderate the effects of alcohol or smoking ( $p$-values of $>0.05$ ).

Table 1 Sample characteristics at baseline, and comparison between those with 13 or less episodes, versus those with more than 13 episodes $(n=108)$

\begin{tabular}{|c|c|c|c|c|}
\hline Sociodemographics & All 108 subjects & $\leq 13$ episodes $^{* *}$ & $>13$ episodes $^{* *}$ & $p$-value* \\
\hline Gender (\% female) & 54.6 & 56.6 & 52.8 & 0.696 \\
\hline Age at intake (mean in years, SD) & $46.1(10.0)$ & $43.5(10.1)$ & $48.6(9.5)$ & $0.008^{*}$ \\
\hline Educational level: $\% \geq$ high school & 51.4 & 45.3 & 59.6 & 0.141 \\
\hline Income (\% >20.000 euro/year) & 36.5 & 31.4 & 43.1 & 0.219 \\
\hline Unable to work (\%) & 50.0 & 50.9 & 49.1 & 0.846 \\
\hline \multicolumn{5}{|l|}{ Clinical characteristics } \\
\hline $\mathrm{BD} \mid(\% \mathrm{BD}|; \% \mathrm{BD} \| \mathrm{l}=100-\% \mathrm{BD}|)$ & 62.0 & 69.8 & 54.7 & 0.109 \\
\hline Liftetime history of rapid cycling (\%) & 17.0 & 5.8 & 26.9 & $0.004^{*}$ \\
\hline First degree relative with $\mathrm{BD}(\%)$ & 40.7 & 37.3 & 45.5 & 0.430 \\
\hline Age at onset of BD (mean in years, SD) & $23.8(9.7)$ & $25.4(10.3)$ & $22.3(8.7)$ & 0.097 \\
\hline Duration of BD (mean in years, SD) & $22.3(11.7)$ & $18.1(10.8)$ & $26.3(10.9)$ & $<0.001^{*}$ \\
\hline Current diagnosis alcohol dependence (\%) & 20.2 & 13.5 & 26.9 & 0.087 \\
\hline Current daily smoking (\%) & 41.7 & 43.4 & 39.6 & 0.693 \\
\hline Current diagnosis drug use/dependence (\%) & 3.7 & 1.9 & 5.7 & 0.308 \\
\hline Current diagnosis anxiety disorder (\%) & 15.7 & 11.3 & 18.9 & 0.278 \\
\hline Lifetime nr. of mood episodes (median, IQR) & $13.5(7.0-46.3)$ & $7.0(4.5-10.0)$ & $45.0(20.0-80.0)$ & $<0.001^{*}$ \\
\hline Uses any medication in the last month (\%) & 92.5 & 90.4 & 94.2 & 0.462 \\
\hline Mean units of alcohol per day at baseline & 2.1 & 2.0 & 2.2 & 0.652 \\
\hline Mean units of tobacco at baseline & 7.3 & 7.6 & 6.8 & 0.722 \\
\hline
\end{tabular}

*Bolded $p$-values denote significance.

**Differences between those with few compared to multiple episodes, based on the median number of episodes of 13 
Table 2 Associations and interaction analyses for alcohol/smoking severity, and mood in BD in one-year follow-up ( $n=108)$

\begin{tabular}{|c|c|c|c|c|c|c|c|c|}
\hline & \multicolumn{4}{|c|}{$\begin{array}{l}\text { Number of depressive days per year } \\
95 \% \mathrm{Cl}^{\mathrm{b}}\end{array}$} & \multicolumn{4}{|c|}{$\begin{array}{l}\text { Number of (hypo+)manic days per year } \\
95 \% \mathrm{Cl}^{\mathrm{b}}\end{array}$} \\
\hline & $\overline{\beta^{b}}$ & Lower bound & Upper bound & $p$-value ${ }^{*}$ & $\overline{\beta^{b}}$ & Lower bound & Upper bound & $p$-value* \\
\hline Alcohol use $^{a}$ & 0.961 & 0.791 & 1.168 & 0.687 & 0.994 & 0.843 & 1.171 & 0.938 \\
\hline \multicolumn{9}{|c|}{ Interaction of alcohol use by quartile $e^{a}$. } \\
\hline First quartile $e^{c}$ & 0.819 & 0.448 & 1.496 & 0.512 & 2.003 & 1.225 & 3.274 & 0.006 \\
\hline Second quartile ${ }^{c}$ & 0.812 & 0.579 & 1.140 & 0.226 & 0.713 & 0.539 & 0.944 & 0.019 \\
\hline Third quartile ${ }^{c}$ & 1.004 & 0.708 & 1.426 & 0.980 & 0.885 & 0.659 & 1.190 & 0.416 \\
\hline Fourth quartile & 1.267 & 0.922 & 1.741 & 0.142 & 1.228 & 0.939 & 1.607 & 0.132 \\
\hline Smoking ${ }^{a}$ & 1.040 & 1.003 & 1.079 & 0.033 & 0.982 & 0.952 & 1.013 & 0.256 \\
\hline \multicolumn{9}{|c|}{ Interaction of smoking by quartile $e^{a}$. } \\
\hline First quartile ${ }^{c}$ & 0.999 & 0.893 & 1.118 & 0.988 & 1.064 & 0.967 & 1.170 & 0.201 \\
\hline Second quartile ${ }^{c}$ & 0.994 & 0.914 & 1.080 & 0.878 & 1.021 & 0.952 & 1.095 & 0.553 \\
\hline Third quartile & 0.965 & 0.893 & 1.042 & 0.358 & 0.928 & 0.871 & 0.989 & 0.021 \\
\hline Fourth quartile $e^{c}$ & 1.043 & 0.952 & 1.142 & 0.365 & 1.052 & 0.976 & 1.135 & 0.182 \\
\hline
\end{tabular}

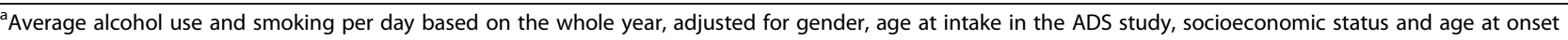
of BD.

*Bolded $p$-values denote significance.

${ }^{b}$ Analyses over natural logarithmic transformed values; presented values are the back-transformed values.

'In each analysis, the effect of the mentioned quartile is compared to the other three quartiles as reference categories. Quartiles refer to $<7,7-13,14-44$ and $>44$ previous mood episodes, respectively

\section{Discussion}

This paper aimed to examine whether the number of previous mood episodes moderates the association between alcohol and smoking on one hand, and the number of depressive, hypomanic and manic days on the other hand, in a one year follow up study of daily life chart scores. First, the overall analyses revealed that an increase in average tobacco consumption per day in a whole year increased the number of depressive days in that year. By contrast, the number of hypomanic and manic days showed no relationship with smoking in the overall analysis, and alcohol consumption was neither related to the number of depressive, hypomanic or manic days. Second, the interaction analyses showed that the number of previous mood episodes moderated the associations between both alcohol use and smoking, and mood. Our most robust finding was that in those with $<7$ mood episodes (first quartile of number of episodes), one unit increase in average alcohol consumption per day resulted in an adverse and large increase in the number of hypomanic and manic days in that year. By contrast, although to a lesser extent, a decrease in the number of hypomanic and manic days per increased unit of alcohol consumption was found in those subjects with 7 to 13 previous mood episodes (second quartile). A decreased number of hypomanic and manic days was also found per increased unit of tobacco consumption in subjects with 14 to 44 previous mood episodes (third quartile).

Our finding that alcohol is adversely associated with the number of hypomanic and manic days in those with relatively few episodes (first quartile) corroborates our initial hypothesis. We hypothesized that the relationship between alcohol use and smoking on the one hand, and mood on the other are most pronounced in those subjects who have experienced fewer compared to multiple lifetime mood episodes, which is based on Post et al.'s kindling theory [20-22] that states that the impact of exogenous stressors progressively declines with more mood episodes. Likewise, Kendler et al. showed that up to the first nine episodes are linked to stressors and less thereafter [22], although the primary outcome in their analysis was an affective episode, not number of days ill. Thus, the "window of vulnerability" to the adverse relationship between alcohol use and the manic polarity may be comparable to that of other stressors, which is in line with the kindling hypothesis [20-22].

Our finding that this adverse and strong relationship exclusively occurred in the first quartile of mood episodes may be explained by a relatively intact responsiveness to the excitatory, stimulating and destabilizing effects of alcohol in those who experienced only a few previous mood episodes. Intact responsiveness to exogenous effects was also found to CBT effects in those with up to twelve mood episodes [23] and to pharmacotherapeutic effects in those with up to ten episodes [24, 25]; not in those with more episodes. Conversely, an increased number of (hypo) manic days may induce a higher alcohol consumption in the first quartile. Increased alcohol consumption may be mediated by the increased impulsivity and/or excessive involvement in pleasurable activities pertinent to (hypo) mania [27]. 
In contrast to this increased number of (hypo) manic days per unit alcohol use in the first quartile, we found that - to a lesser extent - the number of hypomanic and manic days decreased per unit alcohol in those subjects in the second quartile. An explanation might be that a decreased number of (hypo) manic days could lead to an increased alcohol consumption in the second quartile of more experienced patients, in an unsuccessful attempt to self-medicate [38] and induce an elevated mood.

Likewise, with each unit increase in tobacco consumption, we also found a modestly decreased number of hypomanic and manic days in those subjects in the third quartile of mood episodes. An explanation may be that, akin to the use of alcohol in the second quartile, a decreased number of (hypo) manic days leads to increased smoking in order to self-medicate [38] and induce positive feelings [27]. Furthermore, smokers may attempt to compensate for the cognitive disturbances [39] that are more frequent among those with more progressed BD [40]. Altogether, the modest effects on (hypo) mania later in the course of illness need further exploration.

In our sample, an increase in average tobacco consumption was independently associated with an increase in the number of depressive days in the whole year. A growing body of literature supports an adverse relationship between smoking and course in BD [11, 12, 41], and the risk of depressive morbidity among smokers is also demonstrated in psychiatric disorders closely related to the bipolar spectrum [42]. Likewise, more severe levels of smoking predicted the onset of major depression [36-39] in well-designed studies that included large samples, adjusted for confounding, and attempted to exclude shared vulnerability factors [43-46]. Alternatively, greater depressive morbidity may cause increased smoking as a mode of self-medication [38], or depression may reduce the success of smoking cessation [6].

Although the relation between smoking and mood is likely to be multifactorial and multidirectional [7, 14], unidirectional effects of smoking on depressive days in BD may be mediated by several neurochemical mechanisms. First, nicotine is a nicotinic cholinergic receptor agonist that affects acetylcholine, catecholamine and dopamine systems [40, 42, 47], and these systems play an etiologic role in depression [48] including bipolar depression [49]. Second, polycyclic aromatic hydrocarbons (PACs) and other compounds in cigarette smoke induce oxidative stress, and elevated markers of oxidative stress are positively correlated with the severity of depression [50]. Third, PACs in cigarettes can interfere with the efficacy of pharmacotherapy in BD $[25,45,51]$ by lowering serum levels of several psychotropic drugs through hepatic enzyme induction [52].

Contrary to our initial hypothesis we did not find any overall association between alcohol and depression. The absence of such an overall effect is in agreement with some previous studies [13, 18]. The explanation suggested by Van Zaane et al. [17], that alcohol may have an effect on mood only in the early course of BD, is supported by our finding that the most robust relationship between alcohol use and (hypo)mania occurred exclusively in those with few previous mood episodes and not in the overall sample.

Strengths of our study are the daily, prospective and monthly double-checked measurements, and a detailed assessment of baseline alcohol use and smoking levels. Limitations are the representativeness of our sample, as all participants were Dutch [53] and treatment adherent [17]. In addition, one could argue that our analyses should have been adjusted for percentage, type or number of medication used, however we considered this of no additional value due to the large percentage of $92.5 \%$ of medication use in our sample, no variation in medication adherence, and the complex nature of response to medication in BD [54]. Furthermore, we only considered current substance use and did not take into account the possible lifetime-accumulated effects of substance use on sensitization processes $[20,50,55]$. For future research, it would be informative to investigate short-term co-variation of daily mood scores during a year with daily alcohol and drugs consumption and other behavioral information that can be collected with life charts, such as hours of sleep and life events.

\section{Conclusion}

Our study indicates that the number of previous mood episodes moderates the association between alcohol use and smoking, and mood. Although these findings should be interpreted with caution, the adverse and strong relationship between alcohol and (hypo)mania in those with few lifetime mood episodes is in agreement with the kindling hypothesis. This may suggest that particularly patients early in the course of bipolar disorders are vulnerable to the adverse interaction between alcohol and (hypo)mania. The opposite and smaller associations between alcohol use and (hypo)mania, and between smoking and (hypo)mania in those with more previous mood episodes need further replication and exploration of possible underlying mechanisms. The adverse overall relationship between smoking and depression, regardless of the direction of the effect, deserves major attention from clinicians.

\section{Acknowledgements}

Not applicable.

\section{Funding}

This study was funded by Geestelijke Gezondheidszorg (GGZ; Institute of Psychiatry and Mental Health) inGeest, Bennebroek, NL; Altrecht GGZ, Utrecht, NL; Stichting tot Steun VCVGZ, Arnhem, NL; and by unrestricted grants from Eli Lilly International, USA, and Bristol-Myers Squibb BV, NL. The Funding sources had no further role in in the design of the study and collection, analysis, and interpretation of data nor in writing the manuscript. 


\section{Availability of data and materials}

The datasets analysed during the current study available from the corresponding author on reasonable request.

\section{Authors' contributions}

WtM conducted the statistical analyses together with SD. WtM prepared the first draft version of the article, with the aid of SD. JVZ collected all the raw data. AJB and RK actively participated in formulation of the research question and hypothesis, and in the preparation of the manuscript. All authors actively participated in preparation and revision of the paper, and all authors read and approved the final manuscript.

\section{Competing interests}

JvZ has received unrestricted grants for the Study on the Effect of Alcohol, Drugs, and Stimulants (ADS) in Patients With Bipolar Disorders and Mood Disorder Questionnaire (MDQ) Study on Screening for Bipolar Disorders in Patients Who Seek Treatment in Addiction Centers: Performance of the Mood Disorder Questionnaire in an Addiction Population from Stichting tot Steun Vereniging tot Christelijke Verzorging van Geestes- en Zenuwzieken (VCVGZ), The Netherlands (NL; ADS and MDQ studies), Eli Lilly International (ADS study), and Bristol-Myers Squibb Besloten Vennootschap (BV; Limited Company; ADS study); and participated in the speakers fee accredited symposia for AstraZeneca (NL), Eli Lilly (NL), Janssen-Cilag (BV, NL), and Organon (NL). RK has received grant support from AstraZeneca and received speakers fees from AstraZeneca, Lundbeck and BristolMyersSquibb. AJB participated in the Lundbeck - speakers bureau. SD and WtM have no competing interests relative to the article.

\section{Consent for publication}

Not applicable.

\section{Ethics approval and consent to participate}

The ADS study was approved by the Medical Ethical Review Committee of the University Medical Center Utrecht, The Netherlands. All subjects gave written informed consent after full explanation of the study.

\section{Publisher's Note}

Springer Nature remains neutral with regard to jurisdictional claims in published maps and institutional affiliations.

Received: 20 September 2016 Accepted: 30 April 2017

Published online: 15 May 2017

\section{References}

1. Pedersen $C B$, Mors $O$, Bertelsen A, Waltoft BL, Agerbo E, McGrath JJ, Mortensen PB, Eaton WW. A comprehensive nationwide study of the incidence rate and lifetime risk for treated mental disorders. JAMA psychiatry. 2014;71(5):573-81.

2. Kupka RW, Altshuler LL, Nolen WA, Suppes T, Luckenbaugh DA, Leverich GS, Frye MA, Keck PE, Mcelroy SL, Grunze H, Post RM. Three times more days depressed than manic or hypomanic in both bipolar I and bipolar II disorder. Bipolar Disord. 2007;9(3):531-5.

3. Perlis RH, Ostacher MJ, Patel JK, Marangell LB, Zhang H, Wisniewski SR, Ketter TA, Miklowitz DJ, Otto MW, Gyulai L, Reilly-Harrington NA, Nierenberg AA, Sachs GS, Thase ME. "Predictors of recurrence in bipolar disorder: Primary outcomes from the Systematic Treatment Enhancement Program for Bipolar Disorder (STEP-BD),". Am J Psychiatry. 2006;163:217-224.

4. Solomon D, Keitner G, Willer I, Shea M, Keller M. Course of Illness and Maintenance Treatments for Patients With Bipolar Disorder. J. Clin. Psychiatry. 1994;56:5-13.

5. Di Florio A, Craddock N, van den Bree M. Alcohol misuse in bipolar disorder A systematic review and meta-analysis of comorbidity rates. Eur Psychiatry. 2014;29(3):117-24

6. Heffner JL, Strawn JR, DelBello MP, Strakowski SM, Anthenelli RM. The cooccurrence of cigarette smoking and bipolar disorder: phenomenology and treatment considerations. Bipolar Disord. 2011;13(4):439-53.

7. Rakofsky JJ, Dunlop BW. Do alcohol use disorders destabilize the course of bipolar disorder? J Affect Disord. 2013;145(1):1-10.

8. Kessing LV. The effect of the first manic episode in affective disorder: A case register study of hospitalised episodes. J Affect Disord. 1999;53:233-9.
9. Simhandl C, Radua J, Konig B, Amann BL. Prevalence and impact of comorbid alcohol use disorder in bipolar disorder: A prospective follow-up study. Psychiatry: Aust. New Zeal. J; 2015.

10. Waxmonsky JA, Thomas MR, Miklowitz DJ, Allen MH, Wisniewski SR, Zhang $\mathrm{H}$, Ostacher MJ, Fossey MD. Prevalence and correlates of tobacco use in bipolar disorder: Data from the first 2000 participants in the Systematic Treatment Enhancement Program. Gen Hosp Psychiatry. 2005;27:321-8.

11. Ostacher MJ, Nierenberg AA, Perlis RH, Eidelman P, Borrelli DJ, Tran TB, Ericson GM, Weiss RD, Sachs GS. The relationship between smoking and suicidal behavior, comorbidity, and course of illness in bipolar disorder. J. Clin. Psychiatry. 2006;67:1907-11.

12. Dodd S, Brnabic AJM, Berk L, Fitzgerald PB, De Castella AR, Filia S, Filia K, Kelin K, Smith M, Montgomery W, Kulkarni J, Berk M. A prospective study of the impact of smoking on outcomes in bipolar and schizoaffective disorder. Compr Psychiatry. 2010;51(5):504-9.

13. DelBello MP, Hanseman D, Adler CM, Fleck DE, Strakowski SM. "Twelvemonth outcome of adolescents with bipolar disorder following first hospitalization for a manic or mixed episode,". Am J Psychiatry. 2007;164: 582-590.

14. Flensborg-Madsen Trine T, Bay von Scholten M, Flachs EM, Mortensen EL, Prescott $E$, Tolstrup JS. Tobacco smoking as a risk factor for depression. A 26-year population-based follow-up study. J Psychiatr Res. 2011;45:143-9.

15. Nery FG, Stanley JA, Chen H-H, Hatch JP, Nicoletti MA, Serap Monkul E, Lafer B, Soares JC. "Bipolar disorder comorbid with alcoholism: A $1 \mathrm{H}$ magnetic resonance spectroscopy study," J Psychiatr Res, vol. 44, no. 5, pp. 278-285, 2010.

16. Fleck DE, Arndt S, DelBello MP, Strakowski SM. Concurrent tracking of alcohol use and bipolar disorder symptoms. Bipolar Disord. 2006;8(i):338-44.

17. van Zaane J, van den Brink W, Draisma S, Smit JH, Nolen WA. The effect of moderate and excessive alcohol use on the course and outcome of patients with bipolar disorders: a prospective cohort study. J Clin Psychiatry. Jul. 2010;71(7):885-93.

18. Kreinin A, Novitski D, Rabinowitz D, Weizman A, Grinshpoon A. Association between tobacco smoking and bipolar affective disorder: Clinical, epidemiological, cross-sectional, retrospective study in outpatients. Compr Psychiatry. 2012:53(3):269-74.

19. Post RM. Epigenetic basis of sensitization to stress, affective episodes, and stimulants: implications for illness progression and prevention. Bipolar Disord. 2016;18(4):315-24.

20. Post RM. Kindling and sensitization as models for affective episode recurrence, cyclicity, and tolerance phenomena. Neurosci Biobehav Rev. 2007;31:858-73.

21. Post RM. Transduction of psychosocial stress into the neurobiology of recurrent affective disorder. Am J Psychiatry. 1992;149(8):999-1010.

22. Kendler KS, Thornton LM, Gardner CO. Stressful life events and previous episodes in the etiology of major depression in women: An evaluation of the 'kindling' hypothesis. Am J Psychiatry. 2000;157(8):1243-51.

23. Scott J, Paykel E, Morriss R, Bentall R, Kinderman P, Johnson T, Abbott R, Hayhurst H. Cognitive-behavioural therapy for severe and recurrent bipolar disorders: randomised controlled trial. Br J Psychiatry. 2006;188:313-20.

24. Berk M, Brnabic A, Dodd S, Kelin K, Tohen M, Malhi GS, Berk L, Conus P, McGorry PD. Does stage of illness impact treatment response in bipolar disorder? Empirical treatment data and their implication for the staging model and early intervention. Bipolar Disord. 2011;13:87-98.

25. Swann AC, Bowden CL, Calabrese JR, Dilsaver SC, Morris DD. Differential effect of number of previous episodes of affective disorder on response to lithium or divalproex in acute mania. Am J Psychiatry. 1999;156(8):1264-6.

26. van Zaane J, van de Ven PM, Draisma S, Smit JH, Nolen WA, van den Brink W. Effect of alcohol use on the course of bipolar disorder: one-year followup study using the daily prospective Life Chart method. Bipolar Disord. Jun. 2014;16(4):400-9.

27. M. B. et First, R. L. Spitzer, M. Gibbon, and J. B. W. Williams, Structured Clinical Interview for DSM-IV Axis I Disorders, Clinician Version (SCID-CV). 1997.

28. Spearing MK, Post RM, Leverich GS, Brandt D, Nolen WA. Modification of the Clinical Global Impressions (CGI) scale for use in bipolar illness (BP): The CGIBP. Psychiatry Res. 1997;73:159-71.

29. Leverich GS, Nolen WA, Rush AJ, McElroy SL, Keck PE, Denicoff KD, Suppes T, Altshuler LL, Kupka R, Kramlinger KG, Post RM. The Stanley Foundation Bipolar Treatment Outcome Network: I. Longitudinal methodology. J Affect Disord. 2001;67:33-44.

30. Denicoff KD, Leverich GS, Nolen WA, Rush AJ, McElroy SL, Keck PE, Suppes T, Altshuler LL, Kupka R, Frye MA, Hatef J, Brotman MA, Post RM. Validation 
of the prospective NIMH-Life-Chart Method (NIMH-LCM-p) for longitudinal assessment of bipolar illness. Psychol Med. 2000;30(1921):1391-7.

31. Nolen WA, Luckenbaugh DA, Altshuler LL, Suppes T, McElroy SL, Frye MA, Kupka RW, Keck PE, Leverich GS, Post RM. Correlates of 1-year prospective outcome in bipolar disorder: Results from the Stanley Foundation Bipolar Network. Am J Psychiatry. 2004;161(12):1447-54.

32. Grant BF, Goldstein RB, Saha TD, Chou SP, Jung J, Zhang H, Pickering RP, Ruan WJ, Smith SM, Huang B, Hasin DS. Epidemiology of DSM-5 Alcohol Use Disorder. JAMA Psychiatry. 2015;20852(8):1-10

33. Arnold LM. Gender differences in bipolar disorder. Psychiatr Clin N Am. 2003;26(3):595-620.

34. Baldessarini RJ, Tondo L, Vázquez GH, Undurraga J, Bolzani L, Yildiz A, Khalsa HMK, Lai M, Lepri B, Lolich M, Maffei PM, Salvatore P, Faedda GL, Vieta E, Tohen M. Age at onset versus family history and clinical outcomes in 1, 665 international bipolar-I disorder patients. World Psychiatry. 2012;11(1):40-6.

35. Perlis RH, Dennehy EB, Miklowitz DJ, Delbello MP, Ostacher M, Calabrese JR, Ametrano RM, Wisniewski SR, Bowden CL, Thase ME, Nierenberg AA, Sachs G. Retrospective age at onset of bipolar disorder and outcome during twoyear follow-up: Results from the STEP-BD study. Bipolar Disord. 2009;11(4):391-400.

36. Cate Carter TD, Mundo E, Parikh SV, Kennedy JL. Early age at onset as a risk factor for poor outcome of bipolar disorder. J Psychiatr Res. 2003;37(4):297-303.

37. Kupka RW, Luckenbaugh DA, Post RM, Suppes T, Altshuler LL, Keck PE, Frye MA, Denicoff KD, Grunze H, Leverich GS, McElroy SL, Walden J, Nolen WA. Comparison of rapid-cycling and non-rapid-cycling bipolar disorder based on prospective mood ratings in 539 outpatients. Am J Psychiatry. 2005;162: 1273-80.

38. Bolton JM, Robinson J, Sareen J. Self-medication of mood disorders with alcohol and drugs in the National Epidemiologic Survey on Alcohol and Related Conditions. J Affect Disord. 2009;115:367-75.

39. Ospina LH, Russo M, Nitzburg GM, Cuesta-Diaz A, Shanahan M, PerezRodriguez MM, Mcgrath M, Levine H, Mulaimovic S, and Burdick KE. The effects of cigarette smoking behavior and psychosis history on general and social cognition in bipolar disorder. Bipolar Disord. 2016;18(6):528-538.

40. Berk M, Berk L, Dodd S, Cotton S, Macneil C, Daglas R, Conus P, Bechdolf A, Moylan S, Malhi GS. Stage managing bipolar disorder. Bipolar Disord. 2014;16:471-7.

41. Haug JM, Waxmonsky J, Olincy A, Martin L. Tobacco use in bipolar disorder. J Investig Med. 2010;58(1):240.

42. Adam D. On the spectrum. Nature. 2013;496:6-8.

43. Boden JM, Fergusson DM, Horwood LJ. Cigarette smoking and depression: Tests of causal linkages using a longitudinal birth cohort. Br J Psychiatry. 2010;196:440-6.

44. Khaled SM, Bulloch AG, Williams JV, Hill JC, Lavorato DH, Patten SB. Persistent heavy smoking as risk factor for major depression (MD) incidence - Evidence from a longitudinal Canadian cohort of the National Population Health Survey. J Psychiatr Res. 2012;46:436-43.

45. Klungsøyr O, Nygård JF, Sørensen T, Sandanger I. Cigarette smoking and incidence of first depressive episode: An 11-year, population-based followup study. Am J Epidemiol. 2006;163(5):421-32.

46. Pasco JA, Williams LJ, Jacka FN, Ng F, Henry MJ, Nicholson GC, Kotowicz MA, Berk M. Tobacco smoking as a risk factor for major depressive disorder: population-based study. Br J Psychiatry. 2008;193:322-6.

47. Berk M, Dodd S, Kauer-Sant'Anna M, Malhi GS, Bourin M, Kapczinski F, Norman T. Dopamine dysregulation syndrome: Implications for a dopamine hypothesis of bipolar disorder. Acta Psychiatr Scand. 2007:116:41-9.

48. Dani JA, De Biasi M. Cellular mechanisms of nicotine addiction. Pharmacol Biochem Behav. 2001;70:439-46.

49. Heffner JL, Delbello MP, Anthenelli RM, Fleck DE, Adler CM, Strakowski SM. Cigarette smoking and its relationship to mood disorder symptoms and cooccurring alcohol and cannabis use disorders following first hospitalization for bipolar disorder. Bipolar Disord. 2012;14:99-108.

50. Yanik M, Erel O, Kati M. The relationship between potency of oxidative stress and severity of depression. Acta Neuropsychiatr. 2004;16(7):200-3.

51. Berk M, Ng F, Wang W, Tohen M, Lubman DI, Vieta E, Dodd S. Going up in smoke: Tobacco smoking is associated with worse treatment outcomes in mania. J Affect Disord. 2008:110:126-34.

52. Desai HD, Seabolt J, Jann MW. Smoking in patients receiving psychotropic medications: a pharmacokinetic perspective. CNS Drugs. 2001;15(6):469-94
53. Post RM, Altshuler L, Kupka RW, McElroy S, Frye MA, Rowe M, Leverich GS, Grunze H, Suppes T, Keck PE, Nolen WA. More pernicious course of bipolar disorder in the United States than in many European countries: Implications for policy and treatment. J Affect Disord. 2014;160:27-33.

54. Post RM, Leverich GS, Kupka RW, Keck PE, Mcelroy SL, Altshuler LL, Frye MA, Rowe M, Grunze H, Suppes T, and Nolen WA. Clinical correlates of sustained response to individual drugs used in naturalistic treatment of patients with bipolar disorder. Compr Psychiatry. 2016;66:146-56.

55. Post RM. Intermittent versus continuous stimulation: Effect of time interval on the development of sensitization or tolerance. Life Sci. 1980;26(16):1275-82.

\section{Submit your next manuscript to BioMed Central and we will help you at every step:}

- We accept pre-submission inquiries

- Our selector tool helps you to find the most relevant journal

- We provide round the clock customer support

- Convenient online submission

- Thorough peer review

- Inclusion in PubMed and all major indexing services

- Maximum visibility for your research

Submit your manuscript at www.biomedcentral.com/submit
Biomed Central 